\title{
Sinomenine, a COX-2 inhibitor, induces cell cycle arrest and inhibits growth of human colon carcinoma cells in vitro and in vivo
}

\author{
HAIBO YANG $^{1}$, PEIHAO YIN ${ }^{2}$, ZHAN SHI $^{1}$, YANCHUN MA ${ }^{3}$, \\ CHENGGEN ZHAO ${ }^{4}$, JAMPU ZHENG ${ }^{3}$ and TENG CHEN ${ }^{2}$ \\ Departments of ${ }^{1}$ Colorectal Surgery, ${ }^{2}$ General Surgery, ${ }^{3}$ Experimental Center and ${ }^{4}$ Oncology, \\ Putuo Hospital, Shanghai University of Traditional Chinese Medicine, Shanghai 200062, P.R. China
}

Received October 23, 2014; Accepted September 22, 2015

DOI: $10.3892 / 01.2015 .3838$

\begin{abstract}
Certain non-steroidal anti-inflammatory drugs may possess anti-tumorigenic effects in certain cancer cell types. Sinomenine (SIN) is an alkaloid from Sinomenium acutum, a Chinese medicinal plant that inhibits inflammatory reactions and that has been used in the treatment of neuralgia and rheumatic diseases. In this study, we investigated the anticancer effects of SIN against colorectal cancer in vitro and in vivo, as well as the underlying mechanisms. The effects of SIN on proliferation, cell cycle progression and cyclooxygenase (COX)-2 expression were examined in human colorectal cancer-derived SW1116 cells. The in vivo effects of SIN were examined in a model of SW1116 tumor xenograft growth in athymic nude mice. Changes in COX-2 expression induced by the biological effects of SIN were analyzed by western blot analysis. The effects of SIN treatment on G1 phase cell cycle regulators in xenografts were analyzed by immunohistochemistry. Our findings demonstrate that SIN inhibits the proliferation of SW1116 cells by promoting their accumulation in the G1 phase, with concomitant suppression of COX-2 expression. Time- and dose-dependent inhibition of tumor growth and reduced toxicity were observed in nude mice administered daily intraperitoneal injections of SIN at doses of 25,50 and $100 \mathrm{mg} / \mathrm{kg}$. SIN-treated tumors also exhibited reduced COX-2 expression, a marked increase in Cip1/p21 protein levels and a decrease in the levels of cyclin D1 and cyclin E. SIN may be an effective chemopreventive agent against colorectal cancer. The growth inhibitory properties of SIN against colorectal cancer may be mediated via a COX-2 inhibitory effect and cell cycle arrest in the G1 phase.
\end{abstract}

Correspondence to: Dr Teng Chen, Department of General Surgery, Putuo Hospital, Shanghai University of Traditional Chinese Medicine, 164 Lanxi Road, Putuo, Shanghai 200062, P.R. China

E-mail: yhbys@126.com

Key words: sinomenine, colorectal cancer, cyclooxygenase-2, cell cycle, SW1116 cells, xenograft tumor

\section{Introduction}

Colorectal cancer is a leading cause of malignant tumor-related mortality in developed countries (1), and is the third most common cancer type in China (2). Every year, 300,000 mortalities from colorectal cancer occur globally $(3,4)$. Chemotherapy with 5-fluorouracil (5-FU) and associated adjuvant agents remains the standard drug treatment regimen against early-stage and advanced colorectal cancers. Despite progress in the elucidation of the carcinogenic processes of colon cancer, more effective treatment regimens based on novel and innovative approaches are required, since the remission rate induced by treatment with 5-FU and associated adjuvant agents is low $(5,6)$. In addition, standard chemotherapy produces numerous systemic adverse reactions, including a decrease in leukocyte and platelet counts $(7,8)$. Hence, more effective and safer therapeutic strategies are urgently required.

Certain non-steroidal anti-inflammatory drugs (NSAIDs) exhibit inhibitory effects on COX-2, and are used extensively for analgesic and antipyretic treatments (9). Previous studies have demonstrated that NSAIDs reduce the risk and mortality of several cancer types $(10,11)$. While their anti-tumorigenic mechanisms are not completely understood, cyclooxygenase (COX)-dependent and COX-independent pathways may play significant roles $(12,13)$. In 2004, a study reported increased cardiovascular toxicity occurring in patients who received the drug Vioxx for longer than 18 months (14). Thus, drugs from herbal/natural sources with COX-2 inhibitory properties that produce fewer side effects are of interest. Sinomenium acutum has a long history of medicinal use in traditional Chinese medicine, and is now commonly used as a COX-2 inhibitor and as an anti-inflammatory agent in mixed herbal decoctions for the treatment of neuralgia and rheumatic diseases $(15,16)$. It is capable of potently releasing histamine in association with the degranulation of mast cells in mammalian tissues. The release of histamine is responsible for the dominant pharmacological actions of sinomenine (SIN) (17), including vasodilatation, increased vascular permeability, acceleration of thoracic and peripheral lymph flow, contraction of the plain muscles, increased peristalsis of the intestines, and stimulation of gastric acid secretion (18). The active pharmacological constituents of Sinomenium acutum include alkaloids, sterols, phospholipids and several other components. Extensive pharmacological and 
clinical research on SIN has primarily focused on the immune, cardiovascular and nervous system (17).

SIN possesses antitumor activity in certain cancer types and is already prescribed to patients with cardiac diseases (19). SIN exhibits a significant apoptotic effect on NCI-H460 cells through the mitochondria-mediated apoptosis pathway. SIN-induced apoptosis is accompanied by the collapse of the mitochondrial membrane potential, the release of cytochrome $c$ and the activation of caspase- 9 and caspase-3. SIN also increases the levels of Bax protein and decreases the levels of Bcl-2 protein in NCI-H460 cells (20). It also induces apoptosis in NCI-H226 and NCI-H522 cells through the activation of pAkt and Perk (21). However, the anti-tumorigenic action of SIN in colon carcinogenesis has not been clearly determined.

The present study examined the anti-tumorigenic effect of SIN from Sinomenium acutum by focusing on the anti-tumorigenic effects and molecular mechanisms of SIN in SW1116 human colon cancer cells. The growth-inhibitory effects of SIN were examined in vitro and in vivo using a nude mouse xenograft model. We hypothesized that the anti-carcinogenic action of SIN might be due to the inhibition of COX-2 expression in the cancer cells and/or effects on cell cycle regulation.

\section{Materials and methods}

Materials. Sinomenine hydrochloride was obtained from Hunan Zhengqing Pharmaceutical Co. Ltd. (Huaihua, Hunan, China). Primary antibodies against COX-2, cyclin D1, cyclin E, Cip1/p21 and Kip1/p27 were purchased from Santa Cruz Biotechnology, Inc. (Santa Cruz, CA, USA). The antibody against GAPDH was purchased from Sigma-Aldrich (St. Louis, MO, USA). The bicinchoninic acid (BCA) protein assay kit was purchased from the Beyotime Institute of Biotechnology (Haimen, China). An enhanced chemiluminescence (ECL) western blotting kit was purchased from Millipore (Billerica, MA, USA). A PrimeScript ${ }^{\mathrm{TM}} \mathrm{RT}$ reagent kit was obtained from Takara Biotechnology Co., Ltd. (Dalian, China). Universal SYBR-Green I was purchased from Bioteke Corporation (Beijing, China). TRIzol reagent was purchased from Invitrogen Life Technologies (Carlsbad, CA, USA). The RNeasy kit was purchased from Qiagen (Hilden, Germany). Diethylpyrocarbonate was purchased from Sigma (Poole, Dorset, UK). All other reagents were widely available commercially. All quantitative polymerase chain reaction (qPCR) experiments were performed on an Applied Biosystems 7900HT Fast Real-Time PCR system (Life Technologies, Grand Island, NY, USA).

Cell culture and synchronization. The human colon adenocarcinoma cell line SW1116 was purchased from the Type Culture Collection of the Chinese Academy of Sciences, Shanghai, China. Cells were maintained in L-15 medium supplemented with $10 \%$ fetal bovine serum (FBS) in a humidified atmosphere of $100 \%$ air at $37^{\circ} \mathrm{C}$. A subculture of cells was processed by enzymatic digestion (trypsin/ethylenediaminetetraacetic acid solution: 0.25/0.02\%). Sinomenine hydrochloride was dissolved in phosphate-buffered saline (PBS) as a $100 \mathrm{mM}$ stock solution and then diluted with the L-15 medium. All experiments were performed using media containing $1 \%$ serum following $24 \mathrm{~h}$ of serum starvation.
This procedure has been effective for the synchronization of cells in the G0 phase in cell cycle studies $(22,23)$.

Cell viability assay. Cell viability was detected using CCK-8. When $70-80 \%$ confluence was reached, SW1116 cells $\left(2 \times 10^{4}\right)$ were cultured in 96-well plates and exposed to various concentrations of $\operatorname{SIN}(1,2,4,8$ and $16 \mathrm{mM})$ for 24,48 or $72 \mathrm{~h}$. L-15 medium $(0 \mathrm{mM})$ was added to the control wells at the various treatment times. The CCK-8 solution (10 $\mu \mathrm{l})$ diluted 1:10 in FBS-free L-15 (100 $\mu \mathrm{l})$ was added to each well and incubated for $3 \mathrm{~h}$ at $37^{\circ} \mathrm{C}$. The absorbance was measured at $450 \mathrm{~nm}$ using a Bio-Rad 680 microplate reader (Bio-Rad Laboratories, Inc., Hercules, CA, USA). The mean optical density (OD) of five wells in the indicated groups was used to calculate the percentage of cell viability as follows: Cell viability $(\%)=$ $\left(\mathrm{OD}_{\text {treatment group }}-\mathrm{OD}_{\text {blank group }}\right) /\left(\mathrm{OD}_{\text {control group }}-\mathrm{OD}_{\text {blank group }}\right) \times 100 \%$. The experiment was performed in triplicate.

Ultrastructure observation. SW1116 cells $\left(4 \times 10^{6}\right)$ were planted in $100-\mathrm{mm}^{2}$ culture dishes and treated with $8 \mathrm{mM}$ SIN for $48 \mathrm{~h}$. The scratched cells were harvested and washed twice with ice-cold PBS, centrifuged $\left(200 \mathrm{x} \mathrm{g}, 4^{\circ} \mathrm{C}, 10 \mathrm{~min}\right)$ and fixed with ice-cold $2.5 \%$ glutaraldehyde for $24 \mathrm{~h}$ at $4^{\circ} \mathrm{C}$, washed twice in PBS, postfixed in $1 \%$ osmium tetroxide in $0.1 \mathrm{M}$ phosphate buffer for $2-3 \mathrm{~h}$ at $4^{\circ} \mathrm{C}$, then double-washed in distilled water. The samples were blocked in warm agar $\left(50^{\circ} \mathrm{C}\right)$, dehydrated in ethanol series $(50,75,95$ and double $100 \%)$ and embedded in 618 epoxy resin. Finally, glass knives were used to obtain ultrathin sections of $90 \mathrm{~nm}$ that were stained with uranyl acetate and lead citrate for observation under transmission electron microscopy (CM120, Philips, Amsterdam, The Netherlands).

Flow cytometry analysis for cell cycle distribution. To synchronize the cell cycle at the G0 boundary, SW1116 cells $\left(4 \times 10^{6}\right)$ were planted in $100-\mathrm{mm}^{2}$ culture dishes and treated with various concentrations of $\operatorname{SIN}(0,4,8,10$ and $16 \mathrm{mM})$ for 24,48 or $72 \mathrm{~h}$. Cells were harvested by brief trypsinization and centrifugation. The cells were washed twice with ice-cold PBS, centrifuged $\left(200 \times \mathrm{g}, 4^{\circ} \mathrm{C}, 10 \mathrm{~min}\right)$ and fixed with ice-cold $70 \%$ ethanol for $4 \mathrm{~h}$. After staining with $50 \mu \mathrm{g} / \mathrm{ml}$ propidium iodide and $500 \mu \mathrm{g} / \mathrm{ml}$ RNase at room temperature for $30 \mathrm{~min}$, the cells were subjected to fluorescence-activated cell sorting with FACScan (Becton Dickinson, Franklin Lakes, NJ, USA) to analyze the cell cycle.

Analysis of COX-2 protein expression by western blot analysis. SW1116 cells $\left(4 \times 10^{6}\right)$ plated in $100-\mathrm{mm}^{2}$ culture dishes were treated with various concentrations of $\operatorname{SIN}(0,4,8$ and $10 \mathrm{mM})$ for 24,48 or $72 \mathrm{~h}$. Proteins were obtained by cell lysis in ice-cold cell radioimmunoprecipitation assay buffer. Total proteins in the supernatant were measured using the BCA protein assay kit (Beyotime). Thirty micrograms of total proteins from each sample were separated by $12 \%$ sodium dodecyl sulfate-polyacrylamide gel electrophoresis. The proteins in the gel were transferred to nitrocellulose membranes and probed with the COX-2 (D5H5) XP ${ }^{\circledR}$ rabbit monoclonal antibody. The immunoblots were developed and visualized using an ECL detection system (Bioshine, Shanghai, China). Each blot was stripped and reprobed with GAPDH antibody as an internal 
control. The signal was visualized using an ECL detection system. Western blot analysis of COX-2 protein levels in tumor tissues from nude mice was performed as described for the western blot analysis of SW1116 cells.

Analysis of COX-2 mRNA expression by qPCR. SW1116 cells $\left(4 \times 10^{6}\right)$ plated in $100-\mathrm{mm}^{2}$ culture dishes were treated with various concentrations of $\operatorname{SIN}(0,4,8,10 \mathrm{mM})$ for 24,48 or $72 \mathrm{~h}$. RNA isolation was followed by qPCR to detect COX-2 mRNA. Total RNA was extracted from all cell lines using the RNeasy kit (Qiagen). Complementary DNA was synthesized from total RNA using the PrimeScript RT reagent kit (Takara Biotechnology Co., Ltd.). qPCR measurement of individual cDNA was performed using SYBR-Green dye to measure the formation of duplex DNA, and the result was normalized to the expression of GAPDH. Amplification was performed by denaturation at $95^{\circ} \mathrm{C}$ for $30 \mathrm{sec}$, followed by 40 cycles of $5 \mathrm{sec}$ at $95^{\circ} \mathrm{C}$ (melting) and $30-34 \mathrm{sec}$ at $60^{\circ} \mathrm{C}$ (annealing and elongation) on an Applied Biosystems 7900HT sequence detection system (Applied Biosystems, Foster City, CA, USA). The primers used were as follows: COX-2 upstream primer, 5'-GGAAACTGTGGCGTGATGGCCG-3'; COX-2 downstream primer, 5'-GTTGGCAGTGGGGACACGGAAG-3' (COX-2 product size, 199 bp); GAPDH upstream primer, 5'-GCTGGTGGTAGGAATGTTCC-3'; GAPDH downstream primer, 5'-CAGCATCGATGTCACCATAG-3' (GAPDH product size, $140 \mathrm{bp}$ ). The qPCR analysis of COX-2 mRNA in tumor tissues from nude mice was performed as described for SW1116 cells.

Tumor xenografts in nude mice. The experimental procedures were approved by the Animal Care and Use Committee of Shanghai University of Traditional Chinese Medicine and conformed to the international standards on the ethical treatment of animals. Balb/c nu/nu mice (male, body mass 16-20 g) were purchased from Shanghai Super-B\&K Laboratory Animal Co. Ltd. (Shanghai, China). The mice were maintained under sterile and pathogen-free conditions in isolated pathogen-free ventilation chambers at an ambient temperature of $20-22^{\circ} \mathrm{C}$ with $45-50 \%$ relative humidity. The animal rearing facility was maintained on a 12-h light-dark cycle. All animals were given free access to sterilized food and water and were habituated for 7 days before experimentation.

Mice were randomly assigned to the control and treatment groups. The treatment regimens were as follows $(n=8)$ : control group, intraperitoneal (IP) injection with normal saline $(0.2 \mathrm{ml})$ once daily (days $0-30)$; SIN treatment group, IP injection with various doses of SIN $(25,50$ and $100 \mathrm{mg} / \mathrm{kg})$ once daily (days 0-30); 5-FU group, IP injection with 5-FU (20 mg/kg) once daily (days $0-14$ ). The cell suspension was injected subcutaneously into the right thigh of each animal (at a cell density of $5 \times 10^{6}$ in $200 \mu \mathrm{l}$ PBS). The day of tumor implantation was designated day 0 . Tumors became palpable 10 days after the xenograft procedure. Tumor volume was measured using a digital caliper every 3 days and calculated as (length $\mathrm{x}$ width ${ }^{2}$ ) / 2 (24). Mice were monitored for 40 days following tumor inoculation. The body weight of all animals was recorded throughout the entire experimental to assess drug toxicity. Any mortality during the course of the study was also recorded.
Immunohistochemical analysis of the expression of cyclin D1, cyclin E, Cipl/p21 and Kipl/p27 in nude mice xenografts. All mice were sacrificed by IP injection with an overdose (35 mg/kg) of pentobarbital followed by cervical dislocation. Tumor samples were fixed in $10 \%$ neutral buffered formalin for $12 \mathrm{~h}$ and processed according to standard procedures. Tumor sections were incubated overnight with monoclonal antibodies against cyclin D1, cyclin E, Cip1/p21 or Kip1/p27 at a 1:400 dilution, followed by incubation with a biotinylated anti-mouse secondary antibody. Then sections were exposed to streptavidin-conjugated horseradish peroxidase and 3,3'-diaminobenzidine. Positive controls for each antibody were included to confirm the adequacy of staining for each experiment. The immunohistochemical method and a computer-assisted image analysis system were used to detect the expression of cyclin D1, cyclin E, Cip1/p21 and Kip1/p27 in the tumor tissues of nude mice.

Statistical analysis. Statistical analysis of the data was performed using SPSS version 19.0 (IBM SPSS, Armonk, NY, USA). Student's t-test was used to compare between the mean values of two groups. Data from each group were compared by one-way analysis of variance, followed by the least significant difference test. Final values are expressed as the means \pm standard error of the mean (SEM). $\mathrm{P}<0.05$ was considered to indicate a statistically significant difference.

\section{Results}

Cell viability assays and transmission electron microscopy analysis of SW1116 cells following SIN treatment. SIN inhibited SW1116 cell viability in a dose-dependent manner (Fig. 1). The estimated median effective concentrations (IC50) of SIN after 24, 48 and $72 \mathrm{~h}$ of incubation were 11.75, 9.85 and $7.91 \mathrm{mM}$, respectively. SIN significantly reduced the viability of SW1116 cells at concentrations of 8 and $16 \mathrm{mM}$ (Fig. 1A). We investigated the morphology of SIN-treated cells using transmission electron microscopy. Cells treated with $8 \mathrm{mM}$ SIN for $48 \mathrm{~h}$ exhibited a morphology typical of nuclear chromatin condensation (Fig. 1C) compared with the control cells without drug treatment (Fig. 1B).

SIN causes cell cycle arrest in SW1116 cells. Based on its cell growth inhibitory effect, the effect of SIN on cell cycle progression in SW1116 cells was examined by cell cycle distribution analysis (Fig. 2). Following SIN treatment for 48 h, a significant and dose-dependent accumulation of cells was noted in the G1 phase, with a concomitant decrease in the percentage of cells in the $\mathrm{S}$ phase compared with the control (0 mM SIN; Fig. 2C). Representative flow cytometry scans of the control and SW1116 cells treated with $8 \mathrm{mM}$ SIN for $48 \mathrm{~h}$ are shown in Fig. 2A and B. These clearly indicate an increase in the number of cells in the G1 phase. The effect of SIN treatment for various incubation times $(24,48$ and $72 \mathrm{~h}$ ) on the cell cycle response in SW1116 cells was investigated at concentrations of 4 and $10 \mathrm{mM}$. At a longer treatment time (72 h), G1 arrest was observed compared with shorter treatment times (24 h; Fig. 2D and E). These results suggest that cell cycle arrest (predominantly in G1 phase) induced by SIN underlies its cell growth inhibitory effect in colorectal cancer cells. 
Table I. Tumor volume (in $\mathrm{mm}^{3}$ ) of nude mice xenografts (mean $\pm \mathrm{SEM}$ ).

\begin{tabular}{|c|c|c|c|c|c|c|}
\hline Treatment & Day 15 & Day 18 & Day 21 & Day 24 & Day 27 & Day 30 \\
\hline Control & $156.0 \pm 29.4$ & $222.1 \pm 66.8$ & $280.1 \pm 107.2$ & $311.8 \pm 119.8$ & $383.3 \pm 145.1$ & $456.9 \pm 141.7$ \\
\hline SIN (25 mg/kg) & $97.8 \pm 46.5^{\mathrm{b}}$ & $136.2 \pm 64.6^{\mathrm{b}}$ & $204.6 \pm 99.9^{a}$ & $239.4 \pm 111.4^{\mathrm{a}}$ & $303.0 \pm 172.6$ & $396.6 \pm 227.0$ \\
\hline $\mathrm{SIN}(50 \mathrm{mg} / \mathrm{kg})$ & $104.8 \pm 48.1^{\mathrm{a}}$ & $140.3 \pm 57.7^{b}$ & $191.6 \pm 65.9^{a}$ & $228.8 \pm 80.2^{\mathrm{a}}$ & $307.7 \pm 149.2$ & $393.4 \pm 158.0$ \\
\hline SIN (100 mg/kg) & $80.6 \pm 22.2^{b}$ & $109.2 \pm 44.5^{\mathrm{b}}$ & $159.8 \pm 47.2^{\mathrm{b}}$ & $178.3 \pm 55.5^{\mathrm{b}}$ & $259.7 \pm 98.5$ & $294.4 \pm 129.3$ \\
\hline $5-\mathrm{FU}$ & $56.5 \pm 21.4^{\mathrm{b}}$ & $63.4 \pm 23.6^{\mathrm{b}}$ & $72.7 \pm 28.1^{\mathrm{b}}$ & $104.3 \pm 45.8^{\mathrm{a}}$ & $132.7 \pm 51.4^{\mathrm{b}}$ & $149.0 \pm 69.1^{\mathrm{b}}$ \\
\hline
\end{tabular}

SIN, sinomenine; 5-FU, 5-Fluorouracil. ${ }^{\mathrm{a}} \mathrm{P}<0.05$, ${ }^{\mathrm{b}} \mathrm{P}<0.01$, compared with control.

A

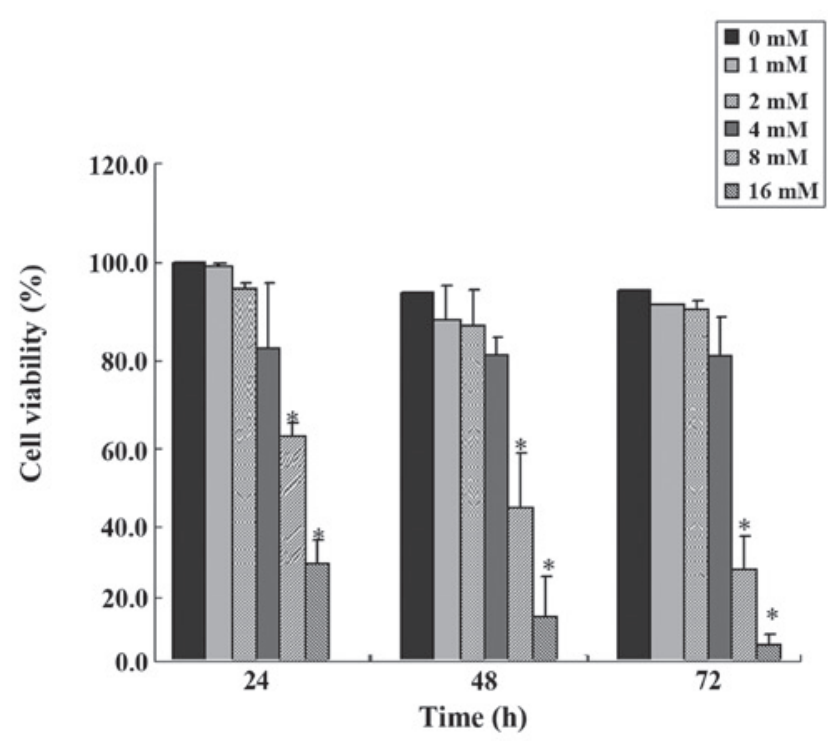

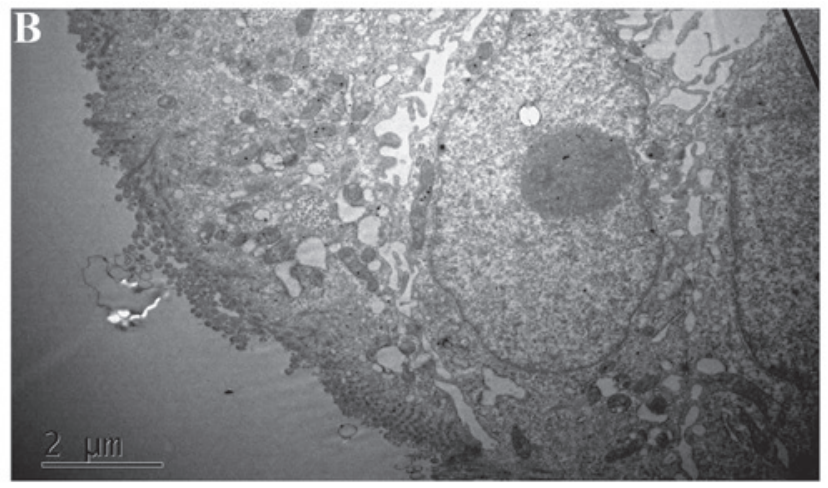

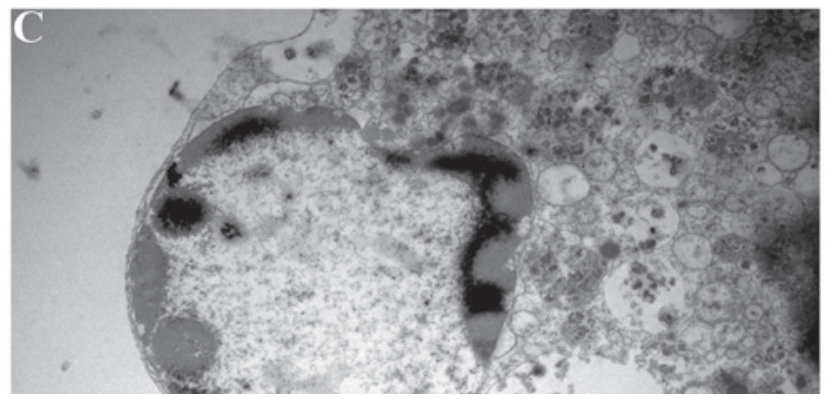

Figure 1. (A) Sinomenine (SIN) reduces viability of SW1116 cells. Cells were treated with increasing concentrations of SIN for 24,48 or 72 h. Cell viability was determined by CCK- 8 assay. The results of three independent experiments are expressed as the percentage of viable cells in the treatment groups with respect to the percentage in the corresponding vehicle-treated control cells ( $0 \mathrm{mM} \mathrm{SIN})$. Error bars represent means $\pm \mathrm{SEM}$. * $\mathrm{P}<0.05$, compared with control. (B) Morphology of control cells without drug treatment. (C) Cells treated with $8 \mathrm{mM}$ SIN for $48 \mathrm{~h}$ exhibit typical morphology of nuclear chromatin condensation.

SIN modulates the expression of COX-2 in SW1116 cells. To determine whether the cell growth inhibitory effect of SIN was correlated with the expression of COX-2, the expression of COX-2 mRNA and protein in SW1116 cells was analyzed. SW1116 cells were exposed to the indicated concentrations of SIN (0, 4, 8 and $10 \mathrm{mM}$ ) for 24, 48 and $72 \mathrm{~h}$. As shown in Fig. 3A and B, COX-2 protein expression significantly decreased in a time- and dose-dependent manner in cells treated with SIN. Consistent with the western blot analysis results, the treatment of SW1116 cells with SIN led to a significant decrease in cytoplasmic COX-2 mRNA expression in a time- and dose-dependent manner (Fig. 3C and D).

Anti-tumorigenic effects of SIN in nude mice xenograft. The anti-tumorigenic effect of SIN on colon cancer was further examined in vivo in nude mice xenografts. The tumor growth inhibition efficacy of SIN was compared with that of the standard chemotherapeutic drug 5-FU. As shown in Tables I and II, treatment with $\operatorname{SIN}(25,50$ and $100 \mathrm{mg} / \mathrm{kg})$ or $5-\mathrm{FU}$
(10 mg/kg) significantly increased tumor growth inhibition from day 15 onwards. On the day of sacrifice (day 18), the group that received a high dose of SIN $(100 \mathrm{mg} / \mathrm{kg})$ demonstrated a tumor suppression rate of $50.8 \%$, approaching that induced by $5-\mathrm{FU}$ alone (Table II). Along with the extension of the intervention time, a trend towards an increase in tumor suppression was observed from days 21-24 onwards.

The body weights of the animals in the control and drug treatment groups were monitored throughout the experimental period to asses drug-induced toxicity. SIN was not observed to cause any significant decrease in the body weight of the mice from days 0-18; however, a significant reduction in body weight was observed on day 24 in the animals treated with a high dose of SIN (Table III).

SIN modulates the expression of COX-2 in nude mice xenografts. To determine whether the tumor growth inhibitory effect of SIN was correlated with COX-2 expression, the effect of SIN treatment on COX-2 protein and mRNA 
A

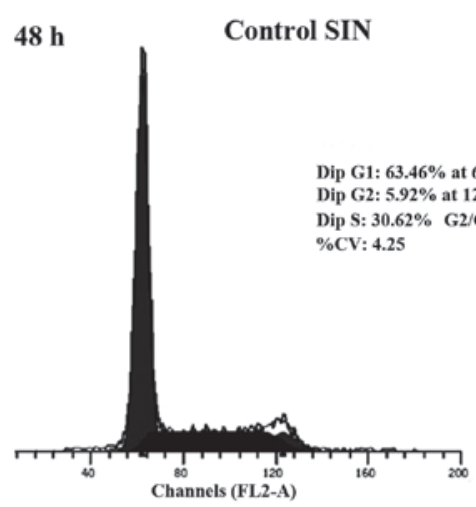

B

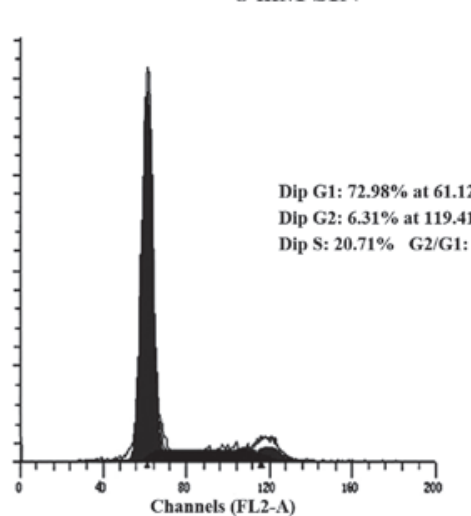

C

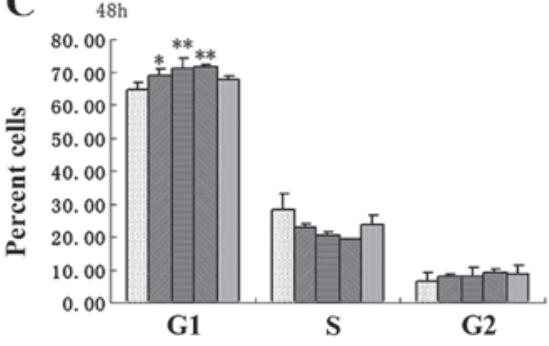

D

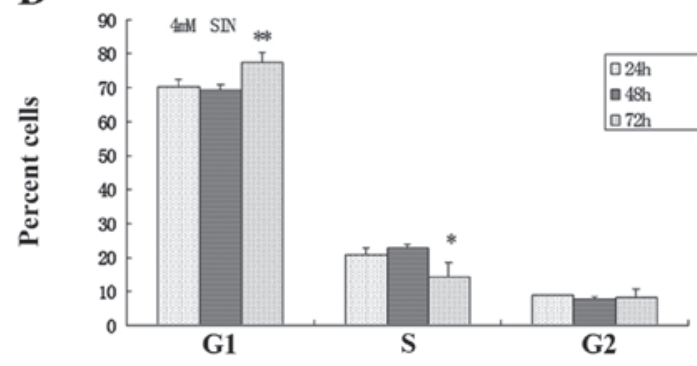

E

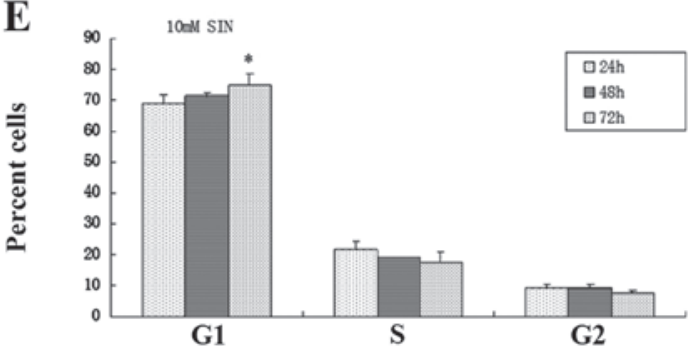

Figure 2. Sinomenine (SIN) induces cell cycle arrest in human colorectal cancer-derived SW1116 cells. (A-C) Cells were treated with either L-15 alone (control) or with varying concentrations of SIN $(4,8,10$ and $16 \mathrm{mM}$ ) for $48 \mathrm{~h}$. Results are expressed as the percentage \pm SEM of cells in each phase in three independent experiments. ${ }^{*} \mathrm{P}<0.05,{ }^{* *} \mathrm{P}<0.01$, compared with control. (D and E) The distribution of SW1116 cells at various phases of the cell cycle following SIN treatment $(4$ and $10 \mathrm{mM})$ for 24,48 and $72 \mathrm{~h}$ was analyzed by flow cytometry. Results are expressed as the percentage \pm SEM of cells in each phase in three independent experiments. ${ }^{*} \mathrm{P}<0.05,{ }^{* *} \mathrm{P}<0.01$, compared with corresponding $24 \mathrm{~h}$ group.

A
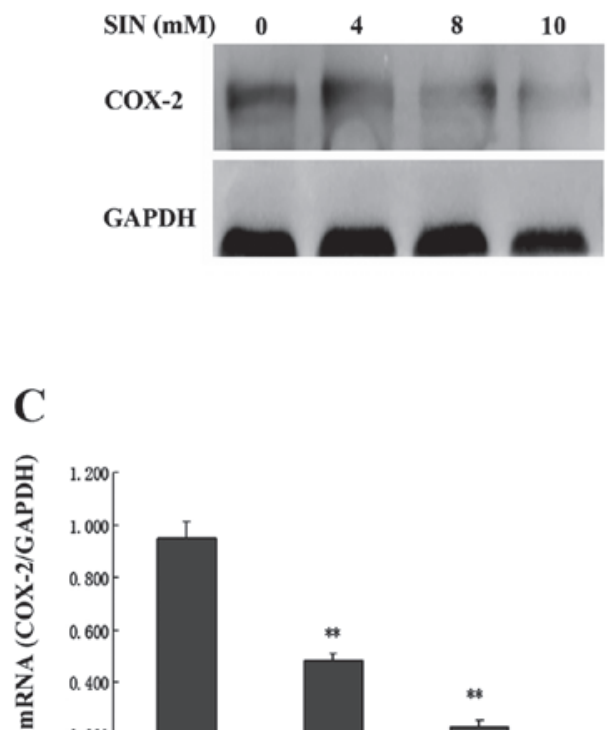

\section{B}

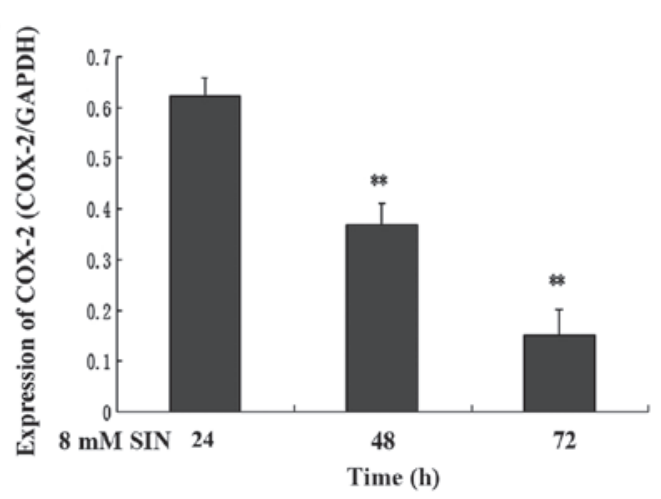

D

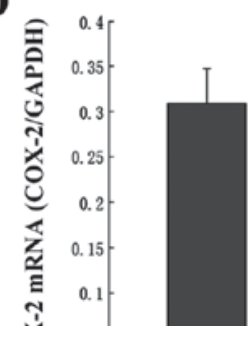

Figure 3. Effects of sinomenine (SIN) on cyclooxygenase (COX)-2 protein and mRNA expression in SW1116 cells. SW1116 cells were treated with varying concentrations of SIN $(0,4,8$ and $10 \mathrm{mM})$ for $48 \mathrm{~h}$ (A and C). SW1116 cells were also treated with SIN $(8 \mathrm{mM})$ for 24, 48 and $72 \mathrm{~h}$. COX-2 protein and mRNA expression was examined by western blot analysis (A and B) and quantitative polymerase chain reaction analysis (C and D). The quantification of COX-2 protein and mRNA expression was normalized to GAPDH levels. Error bars represent means $\pm \mathrm{SEM} .{ }^{*} \mathrm{P}<0.05,{ }^{* * *} \mathrm{P}<0.01$, compared with corresponding control or $24 \mathrm{~h}$ group. 
Table II. Changes in tumor inhibitory rate in the four treatment groups.

Tumor inhibitory rate $(\%)$

\begin{tabular}{lcccccr}
\cline { 2 - 6 } Treatment & Day 15 & Day 18 & Day 21 & Day 24 & Day 27 & Day 30 \\
\hline SIN $(25 \mathrm{mg} / \mathrm{kg})$ & 37.3 & 38.7 & 27.0 & 23.2 & 20.9 & 13.2 \\
SIN $(50 \mathrm{mg} / \mathrm{kg})$ & 32.8 & 36.8 & 31.6 & 26.6 & 19.7 & 13.9 \\
SIN $(100 \mathrm{mg} / \mathrm{kg})$ & 48.3 & 50.8 & 42.9 & 42.8 & 32.2 & 35.6 \\
5-fluorouracil & 63.8 & 71.5 & 74.0 & 66.5 & 66.4 & 67.4
\end{tabular}

SIN, sinomenine.

Table III. Changes in body weight and mortality rate of nude mice with SW1116 xenografts (n=8 per group).

\begin{tabular}{|c|c|c|c|c|c|c|c|}
\hline \multirow[b]{2}{*}{ Treatment } & \multicolumn{6}{|c|}{ Change in body weight } & \multirow[b]{2}{*}{ Mortality } \\
\hline & Day 0 & Day 6 & Day 12 & Day 18 & Day 24 & Day 30 & \\
\hline Control & $18.6 \pm 0.8$ & $19.0 \pm 0.7$ & $20.3 \pm 1.0$ & $20.9 \pm 1.5$ & $21.5 \pm 1.4$ & $21.9 \pm 1.4$ & 1 \\
\hline SIN (25 mg/kg) & $19.2 \pm 0.8$ & $19.1 \pm 1.1$ & $19.9 \pm 0.9$ & $20.3 \pm 1.0$ & $21.5 \pm 1.2$ & $22.1 \pm 1.3$ & 0 \\
\hline SIN (50 mg/kg) & $19.6 \pm 1.0$ & $19.8 \pm 1.2$ & $19.4 \pm 2.9$ & $21.5 \pm 1.3$ & $21.8 \pm 1.4$ & $20.9 \pm 2.6$ & 1 \\
\hline SIN (100 mg/kg) & $17.9 \pm 1.1$ & $18.0 \pm 1.2$ & $18.7 \pm 1.2$ & $18.8 \pm 1.7$ & $19.5 \pm 2.2^{\mathrm{a}}$ & $18.2 \pm 4.0^{\mathrm{b}}$ & 2 \\
\hline 5-fluorouracil & $17.7 \pm 1.0$ & $18.1 \pm 1.1$ & $18.4 \pm 1.7^{\mathrm{a}}$ & $19.1 \pm 3.0$ & $21.4 \pm 1.5$ & $22.2 \pm 1.3$ & 0 \\
\hline
\end{tabular}

SIN, sinomenine. ${ }^{\mathrm{a}} \mathrm{P}<0.05,{ }^{\mathrm{b}} \mathrm{P}<0.01$.

levels was evaluated by western blot analysis and qPCR. As shown in Fig. 4A and B, daily IP injections of SIN at doses of 50 and $100 \mathrm{mg} / \mathrm{kg} / \mathrm{d}$ administered to nude mice resulted in dose-dependent decreases in COX-2 protein expression compared with the control group. Similar results were observed for COX-2 mRNA expression in the treatment group compared with the control group (Fig. 4C).

SIN modulates the expression of cyclin D1, cyclin E,Cip1/p21 and Kipl/p27 in nude mice xenografts. As SIN induced notable cell cycle arrest in the G1 phase in SW1116 cells, we next evaluated the in vivo effect of SIN treatment on cell cycle regulators of the G1 phase. Cyclin D1, Cyclin E, Cip1/p21 and Kip1/p27 expression was immunohistochemically analyzed in tumor samples. Qualitative microscopic examination of Cip1/p21-stained tumor sections revealed an increase in Cip1/p21-positive cells in tumors from SIN-treated $(100 \mathrm{mg} / \mathrm{kg})$ mice compared with tumors from the control group (Fig. 5A). Immunohistochemical analysis of cyclin D1 and cyclin E protein expression in tumor sections revealed a significant decrease $(\mathrm{P}<0.001)$ in cyclin $\mathrm{D} 1$ and cyclin $\mathrm{E}$ immunoreactivity in tumors from SIN-treated mice (Fig. 5C and D). There was no significant difference in the intensity of Kip1/p27-positive staining between tumors from the SIN treatment (100 mg/kg) and control group (Fig. 5B).

\section{Discussion}

The primary aim of the present study was to evaluate the anticancer effects and associated mechanisms of SIN in human colorectal cancer-derived SW1116 cells in vitro and to translate the in vitro findings in an in vivo preclinical model. SW1116 cell culture studies revealed that SIN strongly inhibited SW1116 cell growth in a time- and dose-dependent manner. The growth inhibitory effect was particularly notable in cells treated with a mid-dose and high dose of SIN (8 and $16 \mathrm{mM})$. However, the accumulation of cells in the $\mathrm{G} 1$ phase decreased as the treatment dose of SIN increased to $16 \mathrm{mM}$. It was inferred that cell cycle arrest might not be the only mechanism, and that other factor may also be involved.

Based on the promising in vitro anticancer effects of SIN against SW1116 cells, its efficacy was examined in a preclinical animal model by ectopic implantation of SW1116 xenografts in athymic nude mice, which revealed an anti-tumorigenic effect of SIN. The tumor growth inhibition efficacy of SIN was compared with that of the standard chemotherapeutic drug 5-FU. Treatment with SIN $(25,50$ and $100 \mathrm{mg} / \mathrm{kg})$ significantly increased the tumor inhibition rate from day 15 onwards. On day 18 , treatment with high doses of SIN $(100 \mathrm{mg} / \mathrm{kg})$ resulted in tumor suppression of $50.8 \%$, approaching that induced by 5-FU alone. However, with increasing treatment time, the tumor inhibition rate tended to decrease. We also monitored the body weight of animals throughout the experimental period to assess drug-induced toxicity, which revealed a significant reduction on day 24 in the body weight of animals treated with a high dose of SIN. Based on these results, we inferred that daily IP injection of SIN inhibits the growth of SW1116 tumor xenografts, but that long-term treatment with high-dose SIN (100 mg/kg) should be carefully investigated and considered.

Previous studies have implicated COX-2 in oncogenesis in a number of cancers (25-27), and have demonstrated 

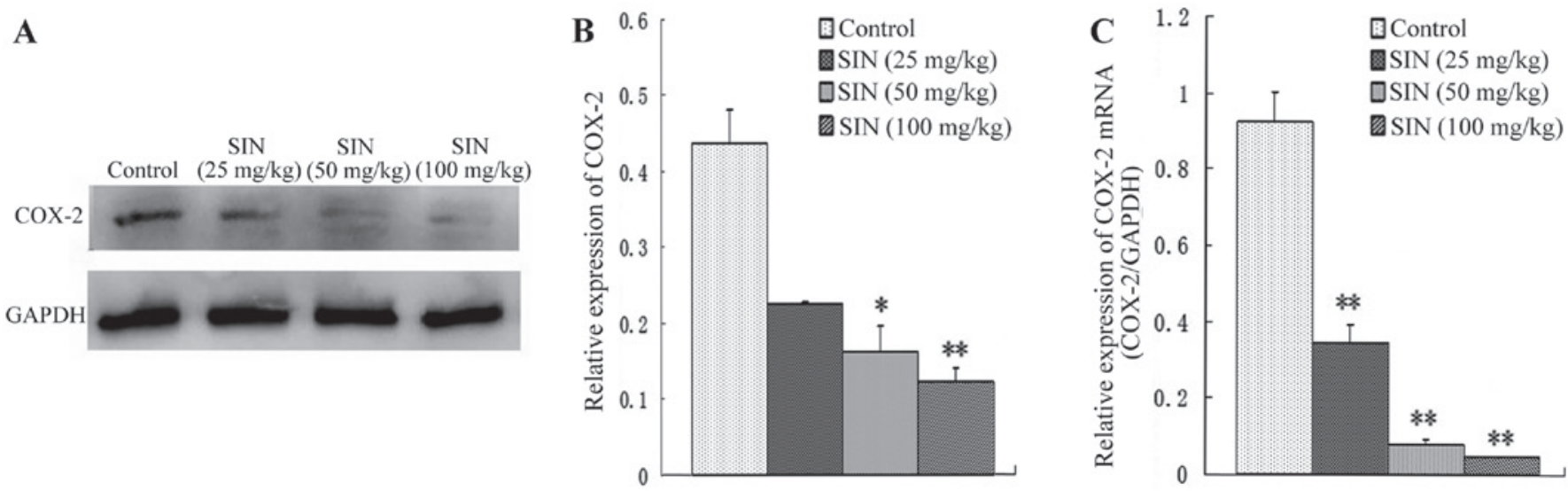

Figure 4. Effects of sinomenine (SIN) on cyclooxygenase (COX)-2 protein and mRNA expression in nude mice xenografts. (A-B) Western blot analysis of the effect of intraperitoneal injection of SIN on COX-2 protein expression; (C) Quantitative polmerase chain reaction analysis of the effect of intraperitoneal injection of SIN on COX-2 mRNA. Quantification of COX-2 protein and mRNA expression was normalized to GAPDH levels. Error bars represent means \pm SEM. ${ }^{*} \mathrm{P}<0.05,{ }^{* *} \mathrm{P}<0.01$, compared with corresponding control group.
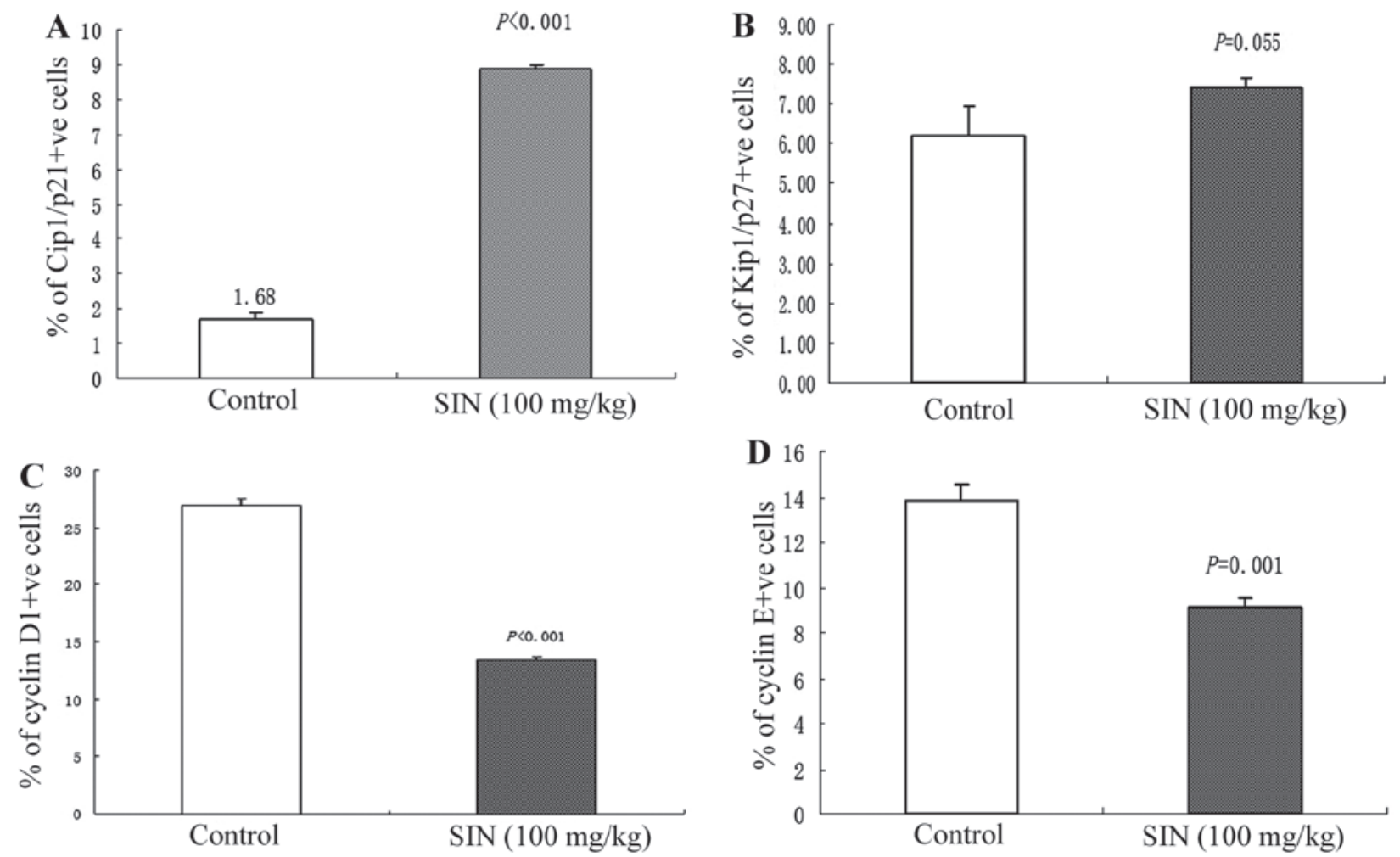

Figure 5. Immunohistochemical analysis of cyclin D1, cyclin E, Cip1/p21 and Kip1/p27 expression in tumor xenografts collected at the end of the study. (A) Increased Cip1/p21-positive immunostaining was observed in tumors from sinomenine (SIN)-treated mice compared with the controls ( $\mathrm{P}<0.001)$. (B) No significant difference in the intensity of Kip1/p27-positive staining was observed between tumors from the SIN treatment $(100 \mathrm{mg} / \mathrm{kg})$ and control group $(\mathrm{P}=0.055)$. (C) The immunostaining intensity of cyclin D1-positive cells was lower in tumors from the SIN-treated mice compared with tumors from control mice $(\mathrm{P}<0.001)$. (D) The immunostaining intensity of cyclin E-positive cells was lower in tumors from SIN-treated mice compared with tumors from the control mice $(\mathrm{P}=0.001)$. All immunohistochemical data are presented as the means \pm SEM of three samples for each group. Significant differences between the control and SIN-treated $(100 \mathrm{mg} / \mathrm{kg})$ groups were calculated by t-test.

that COX-2 inhibitors are effective in the prevention of the development of tumors, including colon cancer. Increased expression of COX-2 is most likely associated with a poor prognosis (28). We demonstrated that SIN inhibits COX-2 expression in SW1116 cells and nude mice xenografts. We thus inferred that COX-2 inhibition may be a significant antitumor mechanism and that COX-2 may be a key target of the drug activity of SIN.
Studies in SW1116 cell culture revealed that SIN may inhibit cell growth via cell cycle arrest, specifically in G1 phase. We next evaluated the effect of SIN treatment on G1 phase cell cycle regulators, including cyclin D1, cyclin E, Cip1/p21 and $\mathrm{Kip} 1 / \mathrm{p} 27$. Cell cycle regulation requires the periodic formation, activation and inactivation of unique protein kinase complexes composed of cyclin (regulatory) and cyclin-dependent kinase (CDK; catalytic) subunits (29). The association of cyclin D1 and 
CDK4, cyclin $\mathrm{E}$ and cdk2 result in rubidium phosphorylation in the G0/G1 and G1/S phase transitions of the cell cycle (30-32). The cdk inhibitors Cip1/p21 and Kip1/p27 have been proposed to exert redundant functions in cell cycle progression (33-36). Cyclin levels are strictly controlled by precise synthesis and degradation at the appropriate time points during cell cycle progression (37). Immunohistochemical analysis revealed an increase in $\mathrm{Cip} 1 / \mathrm{p} 21$ expression and a decrease in cyclin D1 and cyclin E expression, suggesting an effect of SIN on cell cycle arrest in vivo. Abnormal accumulation of cyclin E, cyclin D1 and Cip1/p21 could in turn prevent SW1116 cells from entering the mitotic phase, which might cause a delay in subsequent cell cycle progression. Taken together, the present data demonstrate that SIN has a significant antitumor effect in vivo, and that these molecular alterations by SIN may lead to cell cycle arrest.

In summary, we have demonstrated that SIN inhibits human colon cancer cell growth in vitro and in vivo via COX-2 inhibition and cell cycle arrest in G1 phase. In contrast to standard chemotherapy with cytotoxic drugs, mid/low doses (25 and $50 \mathrm{mg} / \mathrm{kg}$ ) of this herbal molecule induce antitumor effects with reduced toxicity. These results suggest the potential of SIN for development as an alternative treatment option or adjuvant chemotherapeutic agent in colon cancer therapy.

\section{Acknowledgements}

The authors would like to thank Yanchun Ma for technical assistance and Dr Peihao Yin for valuable advice. This study was funded by the Shanghai Education Committee (2012JW66) and by the Putuo district Science and Technology Committee (2012PTKW008).

\section{References}

1. Ekberg M, Callender M, Hamer H and Rogers S: Exploring the decision to participate in the national health service bowel cancer screening programme. Eur J Cancer Prev 23: 391-397, 2014.

2. Hou L, Jiang J, Liu B, Nasca PC, Wu Y, Zou X, Han W, Chen Y, Zhang B, Xue F, et al: Association between smoking and deaths due to colorectal malignant carcinoma: a national population-based case-control study in China. Br J Cancer 110: 1351-1358, 2014

3. Parkin DM, Bray F, Ferlay J and Pisani P: Estimating the world cancer burden: Globocan 2000. Int J Cancer 94: 153-156, 2001.

4. Chatenoud L, Bertuccio P, Bosetti C, Malvezzi M, Levi F, Negri E and La Vecchia C: Trends in mortality from major cancers in the Americas: 1980-2010. Ann Oncol 25: 1843-1853, 2014.

5. Zaniboni A and Labianca R; Gruppo Italiano per lo Studio e la Cura dei Tumori del Digerente: Adjuvant therapy for stage II colon cancer: an elephant in the living room? Ann Oncol 15: 1310-1318, 2004.

6. Rao S and Cunningham D: Adjuvant therapy for colon cancer in the new millenium. Scand J Surg 92: 57-64, 2003.

7. Sinha VR and Honey C: Critical aspects in rationale design of fluorouracil-based adjuvant therapies for the management of colon cancer. Crit Rev Ther Drug Carrier Syst 29: 89-148, 2012.

8. Lotfi-Jam K, Carey M, Jefford M, Schofield P, Charleson C and Aranda S: Nonpharmacologic strategies for managing common chemotherapy adverse effects: a systematic review. J Clin Oncol 26: 5618-5629, 2008.

9. Latimer N, Lord J, Grant RL, O'Mahony R, Dickson J and Conaghan PG: Value of information in the osteoarthritis setting: Cost effectiveness of COX-2 selective inhibitors, traditiona NSAIDs and proton pump inhibitors. Pharmacoeconomics 29: 225-237, 2011.

10. Jacobo-Herrera NJ, Pérez-Plasencia C, Camacho-Zavala E, González GF, Urrutia EL, García-Castillo V and Zentella-Dehesa A: Clinical evidence of the relationship between aspirin and breast cancer risk (review). Oncol Rep 32: 451, 2014.
11. Brasky TM, Liu J, White E, et al: Non-steroidal anti-inflammatory drugs and cancer risk in women: results from the Women's Health Initiative. Int J Cancer 135: 1869-1883, 2014.

12. Wu X, Cai M, Ji F and Lou LM: The impact of COX-2 on invasion of osteosarcoma cell and its mechanism of regulation. Cancer Cell Int 14: 27, 2014.

13. Liggett JL, Zhang X, Eling TE and Baek SJ: Anti-tumor activity of non-steroidal anti-inflammatory drugs: cyclooxygenase-independent targets. Cancer Lett 346: 217-224, 2014.

14. Davies NM and Jamali F: COX-2 selective inhibitors cardiac toxicity: getting to the heart of the matter. J Pharm Pharm Sci 7: 332-336, 2004.

15. Zhang MF, Zhao Y, Jiang KY, et al: Comparative pharmacokinetics study of sinomenine in rats after oral dministration of sinomenine monomer and sinomenium acutum extract. Molecules 19: 12065-12077, 2014.

16. Gao T, Hao J, Wiesenfeld-Hallin Z, et al: Analgesic effect of sinomenine in rodents after inflammation and nerve injury. Eur J Pharmacol 721: 5-11, 2013.

17. Mo ZX, An SL and Zhou JY: Effects of caulis sinomenii and sinomenine on morphine-induced place preference and brain histamine level in mice. Nan Fang Yi Ke Da Xue Xue Bao 26: 1709-1713, 2006 (In Chinese).

18. Yamasaki H: Pharmacology of sinomenine, an anti-rheumatic alkaloid from sinomenium acutum. Acta Med Okayama 30: 1-20, 1976.

19. Candinas D, Mark W, Kaever V, et al: Immunomodulatory effects of the alkaloid sinomenine in the high responder ACI-to-Lewis cardiac allograft model. Transplantation 62: 1855-1860, 1996

20. Jiang T, Zhou L, Zhang W, Qu D, Xu X, Yang Y and Li S: Effects of sinomenine on proliferation and apoptosis in human lung cancer cell line NCI-H460 in vitro. Mol Med Rep 3: 51-56, 2010.

21. Zhou L, Luan H, Liu Q, Jiang T, Liang H, Dong X and Shang H: Activation of PI3K/Akt and ERK signaling pathways antagonized sinomenine-induced lung cancer cell apoptosis. Mol Med Rep 5: 1256-1260, 2012.

22. Kues WA, Anger M, Carnwath JW, et al: Cell cycle synchronization of porcine fetal fibroblasts: effects of serum deprivation and reversible cell cycle inhibitors. Biol Reprod 62: 412-419, 2000.

23. Chen M, Huang J, Yang X, et al: Serum starvation induced cell cycle synchronization facilitates human somatic cells reprogramming. PLoS One 7: e28203, 2012.

24. Tan Y, Sun X, Xu M, et al: Efficacy of recombinant methioninase in combination with cisplatin on human colon tumors in nude mice. Clin Cancer Res 5: 2157-2163, 1999.

25. Tjandrawinata RR, Dahiya R and Hughes-Fulford M: Induction of cyclo-oxygenase-2 mRNA by prostaglandin E2 in human prostatic carcinoma cells. Br J Cancer 75: 1111-1118, 1997.

26. Maekawa M, Sugano K, Sano H, et al: Increased expression of cyclooxygenase-2 to -1 in human colorectal cancers and adenomas, but not in hyperplastic polyps. Jpn J Clin Oncol 28: 421-426, 1998.

27. Hao X, Bishop AE, Wallace M, et al: Early expression of cyclo-oxygenase-2 during sporadic colorectal carcinogenesis. J Pathol 187: 295-301, 1999.

28. Sheehan KM, Sheahan K, O'Donoghue DP, MacSweeney F, Conroy RM, Fitzgerald DJ and Murray FE: The relationship between cyclooxygenase- 2 expression and colorectal cancer. JAMA 282: 1254-1257, 1999.

29. Kõivomägi M and Skotheim JM: Docking interactions: cell-cycle regulation and beyond. Curr Biol 24: R647-R649, 2014.

30. Dorée M and Hunt T: From Cdc2 to Cdk1: when did the cell cycle kinase join its cyclin partner? J Cell Sci 115: 2461-2464, 2002.

31. Sherr CJ and Roberts JM: Living with or without cyclins and cyclin-dependent kinases. Genes Dev 18: 2699-2711, 2004.

32. FisherD, Krasinska L, Coudreuse D and Novák B: Phosphorylation network dynamics in the control of cell cycle transitions. J Cell Sci 125: 4703-4711, 2012.

33. Yoon MK, Mitrea DM, Ou L and Kriwacki RW: Cell cycle regulation by the intrinsically disordered proteins p21 and p27. Biochem Soc Trans 40: 981-988, 2012.

34. Weinberg WC and Denning MF: P21Waf1 control of epithelial cell cycle and cell fate. Crit Rev Oral Biol Med 13: 453-464, 2002.

35. Shankland SJ and Wolf G: Cell cycle regulatory proteins in renal disease: Role in hypertrophy, proliferation and apoptosis. Am J Physiol Renal Physiol 278: F515-F529, 2000.

36. Todd R, Hinds PW, Munger K, Rustgi AK, Opitz OG, Suliman Y and Wong DT: Cell cycle dysregulation in oral cancer. Crit Rev Oral Bio Med 13: 51-61, 2002.

37. Schafer KA: The cell cycle: a review. Vet Pathol 35: 461-478, 1998. 